\title{
O Relato de Caso como Situação Gnosiológica: Reflexões sobre a Prática Diagnóstica em Patologia a Partir de um Caso de Abetalipoproteinemia
}

\section{The Case Report as a Gnosiological Situation: Reflections on Diagnostic Pathology, Based on a Case of Abetalipoproteinemia}

Gil Patrus Mundim Pena

\section{PALAVRAS-CHAVE \\ - Abetalipoproteinemia. \\ - Relato de Caso. \\ - Diagnóstico Patológico.}

\section{KEYWORDS}

- Abetalipoproteinemia.

- Case Report.

- Pathological Diagnosis.

Recebido em: 22/01/2010

Reencaminhado em: 23/03/2010

Aprovado em: 24/03/2010

\section{ABSTRACT}

This article draws on a rare case of abetalipoproteinemia, diagnosed from the pathological findings of a jejunal biopsy, as the point of departure for reflecting on practice in diagnostic pathology. Rather than present a case and comment on its content, as usually happens in case reports, the case, as object of study, can be used as material for reflection on practice. The case is the mediating object of reflection on the practice, allowing an unveiling of reality in which medical practice is a part. 


\section{INTRODUÇÃO}

Os relatos de caso são formas comuns de apresentação do conhecimento em medicina. A literatura médica oferece numerosos exemplos desse tipo de abordagem, como forma de comunicação e transmissão do conhecimento. As revistas especializadas usualmente reservam espaço para a publicação desses relatos, em geral estruturados com uma breve introdução do tema, seguida do relato do caso e discussão ou comentários ${ }^{1}$. Apresentações de caso são também comuns em reuniões científicas de várias especialidades.

Para merecer o relato, o caso a ser publicado (ou apresentado em uma reunião) deve apresentar alguma peculiaridade, que o destaque da rotina ${ }^{1}$. Pode ser a própria raridade do caso ou algum aspecto da apresentação ou da evolução que difere do usualmente esperado.

Na literatura médica e nas apresentações de caso em reuniões de especialidade, o que se vê é a narração do caso, transferindo-se o seu conteúdo aos leitores ou à plateia, em geral sem uma reflexão crítica acerca da prática. Ao ser oferecido como objeto de conhecimento à comunidade de leitores ou assistentes de uma apresentação, os receptores da informação são chamados a memorizar o conteúdo narrado pelo apresentador. Nessa exposição tradicional, não há ato cognoscitivo o objeto do conhecimento é de posse do autor/apresentador. $\mathrm{O}$ ato cognoscitivo dá-se na relação dialógica indispensável à cognoscibilidade dos sujeitos cognoscentes, em torno do mesmo objeto cognoscível (Freire ${ }^{2} 2006$, p.79).

A educação problematizadora parte do conteúdo do caso, como objeto de reflexão sobre a prática, implicando um ato de desvelamento da realidade. Na reflexão acerca da prática, o médico e seu paciente, atores do caso que se narra, não são pessoas abstratas, que habitam um mundo vazio de pessoas, mas pessoas em sua relação com o mundo.

Nessa perspectiva, o "caso" é o mediatizador da reflexão crítica de apresentador e plateia.

Neste ensaio, é narrada a experiência de um relato de caso, apresentado na quarta reunião de especialidades da Sociedade Brasileira de Patologia (São Paulo, SP, 30 de maio de 2009). Mais do que transferir seu conteúdo, o caso foi empregado como objeto de reflexão sobre a prática diagnóstica em patologia.

\section{RELATO DO CASO}

"Paciente de um ano de idade, sexo feminino, encaminhada ao Hospital Infantil João Paulo II, devido a quadro de diarreia, desnutrição importante, com achatamento da curva de peso desde o nascimento. Exame físico mostrando distensão abdominal e desnutrição severa. Peso de 5.200 g. Exames laboratoriais revelando anemia, hipocolesterolemia e hipotrigliceridemia atingindo níveis não detectáveis. Trânsito intestinal: distorção arquitetural grave do jejuno e íleo, espessamento discreto das pregas em jejuno proximal, com floculação do bário, sugestivo de má absorção. Anticorpos antiendomísio e antigliadina negativos. Biópsia jejunal apresentou vilos intestinais apenas levemente hipotróficos, sem linfocitose intraepitelial. Enterócitos apicais com citoplasma claro e vacuolado, indicando diagnóstico de abetalipoproteinemia. Feita a orientação dietética, com uso de ácidos graxos essenciais e suplementação vitamínica, a paciente recebeu alta, para acompanhamento ambulatorial. Medidas de peso anotadas foram de $6.075 \mathrm{~g}, 7.290 \mathrm{~g}, 8.230 \mathrm{~g}$ e 9.060 $\mathrm{g}$, respectivamente aos 2, 5, 12 e 14 meses após a alta. Na última visita, com dois anos e um mês, mediu 78,5 cm."3

\section{COMENTÁRIOS ACERCA DA ABETALIPOPROTEINEMIA}

O estudo da história do conhecimento sobre a abetalipoproteinemia é interessante, por ilustrar como se produz o conhecimento médico, reformulando-se, à medida que novos conhecimentos vão sendo adquiridos ao longo do tempo, e propiciando a reinterpretação de fatos observados anteriormente. De início descrita como uma malformação de hemácias - a acantrocitose —, a abetalipoproteinemia é compreendida hoje como um problema genético, relacionado ao gene da proteína de transferência de triglicéride microssomal. Esse gene foi mapeado no cromossomo 4p22-24.

$\mathrm{O}$ primeiro caso relatado da abetalipoproteinemia foi publicado por Bassen e Kornzweig4 . Para esses autores, o atributo mais marcante da doença, um achado não descrito até então, era a presença de hemácias crenadas, associadas a quadro de retinite pigmentosa atípica, com envolvimento da mácula e de alterações difusas do sistema nervoso central, considerada como ataxia de Friedreich. Os autores mencionam que a paciente, com 18 anos na época do diagnóstico, apresentou, na primeira infância, quadro de má absorção intestinal. Os pais eram primos de primeiro grau, e um irmão mais novo apresentava alterações iniciais na retina e hemácias com mesmo aspecto.

Singer et al. ${ }^{5}$ descrevem outro caso da doença em um menino de 13 anos, também filho de casamento consanguíneo (pais primos de segundo grau, já sugerindo uma herança autossômica recessiva), com quadro de doença celíaca, alterações do sistema nervoso central e alterações das hemácias, que foram denominadas acantócitos. A denominação de acantrócitos para essa alteração eritrocítica foi introduzida por Druez ${ }^{6}$. 
A relação entre as manifestações clínicas e neurológicas, e a ausência de betalipoproteína sérica foi levantada pela primeira vez por Salt et al. ${ }^{7} \mathrm{O}$ defeito básico foi considerado uma incapacidade de sintetizar o peptídeo ApoB do LDL e VLDL. ApoB é a única apoproteina do LDL. Já o VLDL tem uma composição complexa: apoC cerca de $50 \%$; apoB cerca de $35 \%$; apoA, 5\%; ApoE, 10\%.

A incapacidade de sintetizar as lipoproteínas resulta na má absorção de ácidos graxos e vitaminas lipossolúveis da dieta. O tratamento, com a supressão de gorduras da dieta e a suplementação de vitaminas A e E, promovia a estabilização da progressão dos sintomas neurológicos e lesões da retina nos paciente mais velhos, já com alterações. Nos pacientes tratados mais precocemente, evitava-se o aparecimento de sintomas neurológicos ou lesões de retina ${ }^{8}$.

Os resultados negativos de Glickman et al. ${ }^{9}$ na tentativa de demonstrar, por imunofluorescência, a apolipoproteina B na mucosa intestinal pareciam dar suporte à hipótese de um defeito genético ligado à síntese da porção proteica da betalipoproteína ${ }^{9}$. Trabalhos posteriores reuniram evidências da síntese intestinal da apolipoproteina B: Dullaart et al. ${ }^{10}$ conseguiram documentar a expressão de epítopos da apoproteína $\mathrm{B}$ no fígado e no jejuno de um paciente, muito embora a apoB não fosse detectada no plasma. Com esses resultados, foi sugerido que o defeito estaria relacionado não à síntese, mas à secreção da apoB, ou associação apropriada com os lípides, seja no fígado ou no intestino. Permanecia em aberto, nesse momento, a possibilidade de a abetaproteinemia representar uma condição heterogênea, com fenótipos semelhantes, mas defeitos genéticos diferentes.

Com o desenvolvimento de técnicas de DNA e RNA, o gene da apoB pôde ser sequenciado e clonado. $\mathrm{O}$ estudo do gene e do RNA mensageiro da apoB, por Lackner et al., indicou que o mais provável defeito bioquímico estava relacionado ao processamento pós-tradução e à secreção da apoB ${ }^{11}$.

Em 1992, Wetterau et al. ${ }^{12}$ relataram que indivíduos com abetalipoproteinemia não tinham atividade demonstrável da proteína microssomal de transferência de triglicéride e não expressavam o componente de $88 \mathrm{kDa}$ dessa proteína. Essa proteína desempenha um processo-chave no empacotamento da apoB com os lípides. Já em 1993, apareceu o trabalho de Shoulders et al. ${ }^{13}$, que ligava a abetalipoproteinemia à alteração no gene da proteína microssomal de transferência de triglicéride. Mutação homozigótica foi identificada em irmãos com abetalipoproteinemia clássica. A partir de então, outras alterações genotípicas foram descritas, associadas ao gene da proteína microssomal de transferência de triglicéride ${ }^{14}$.

A abetaproteinemia, portanto, inicialmente considerada uma alteração das hemácias (acantrocitose, acantocitose), caracteriza-se bioquimicamente por ausência de betalipoproteína circulante, mas com um defeito genético subjacente localizado em outra proteína, a proteína microssomal de transferência do triglicéride, que desempenha um processo-chave na montagem das lipoproteínas. Com a impossibilidade de exportar as gorduras absorvidas pelo intestino, estas se acumulam nas células epiteliais intestinais e acabam por resultar numa síndrome de má absorção intestinal, com esteatorreia e desnutrição grave. Os níveis séricos de colesterol e triglicérides são particularmente baixos. O quadro anatomopatológico nas biópsias intestinais é tido como quase patognomônico da condição, propiciando oportunidade ao diagnóstico. Associam-se hipovitaminoses das vitaminas lipossolúveis, relacionadas ao desenvolvimento de manifestações oculares e neurológicas. O tratamento consiste em dieta que ofereça ácidos graxos essenciais e suplementação de vitaminas lipossolúveis.

O conhecimento médico é intricado, ramificado e interessante. Nos estudos da literatura médica, com frequencia encontra-se referência a um conhecimento não diretamente relacionado ao tema de interesse, mas que é cativante e pode originar uma investigação adicional. Na investigação sobre a abetalipoproteinemia, foi encontrada referência ao processo de "edição" do RNA, que também ocorre em mamíferos, tendo sido descrito em relação ao RNA da apoB. O "C" é alterado para " $U$ ", criando um códon de parada e versões truncadas da proteína, conforme o tecido (uma proteína liga-se ao mRNA e catalisa a deaminação de $\mathrm{C}$ para U $)^{15}$. A "descoberta" demonstra que o que está escrito nos genes pode ser modificado em processos epigenéticos. A denominação de "dislexia epigenética" bem caberia para essa "troca de letras".

As ferramentas de investigação são outros elementos que fazem parte do estudo de um caso e podem eventualmente merecer menção específica. Nas pesquisas sobre a abetalipoproteinemia, utilizou-se a base de dados Omim (Online Mendelian Inheritance in Man), disponível no site http://www. ncbi.nlm.nih.gov/omim.

\section{REFLEXÕES SOBRE O DIAGNÓSTICO ANATOMOPATOLÓGICO}

Em um caso como este, mais do que o aprendizado específico sobre a abetalipoproteinemia (conteúdo do caso), é possível refletir sobre o processo diagnóstico, propiciando um exercício crítico sobre a prática diagnóstica em patologia. Nessa reflexão crítica sobre a atividade do patologista, consideramos, que:

É a mais alta função do patologista não apenas anexar rótulos corretos às lesões, mas reconstruir o curso dos eventos, desde o início mais precoce da doença, até o momento final da vida. (Boyd apud Hajdu ${ }^{16} 1986$, p. 113) 
A afirmação de Boyd pode ser compreendida de duas maneiras distintas, conforme se considere o exercício da patologia mórbida, da atividade nas salas de necropsia, e o exercício da patologia cirúrgica, diagnóstica, realizada a partir da análise de biópsias (Figura 1).

FIGURA 1

O diagnóstico na anatomia mórbida e na patologia cirúrgica

Anatomia mórbida
Patologia cirúrgica da vida

O momento do diagnóstico na anatomia mórbida, ao final da vida, possibilita reconstruir a cadeia de eventos passados. Na patologia cirúrgica, o diagnóstico representa um ponto de partida, a partir do qual podem ser adotadas condutas que possibilitem modificar a cadeia de eventos futuros.

A anatomia mórbida surgiu na tradição anatômica dos estudos pós-morte, passando por Vesalius, Morgagni e Virchow. É a patologia acadêmica, das salas de necropsia, ligada às universidades, aos departamentos de patologia.

A patologia cirúrgica se desenvolveu sobretudo nos Estados Unidos e surgiu nas salas de cirurgia, estando relacionada fundamentalmente aos serviços diagnósticos de patologia, ligados a hospitais e clínicas. A partir da década de 1950, observou-se, em especial nos Estados Unidos, uma incorporação gradativa dos serviços de patologia cirúrgica e diagnóstica aos departamentos de patologia das universidades ${ }^{17}$.

Entre nós, a patologia, de modo geral, sempre esteve ligada à tradição universitária, acadêmica, onde sempre se deu maior valor à patologia mórbida, de modo que construímos uma cultura diagnóstica a partir dessa tradição. É a tradição das grandes sessões anatomoclínicas, em que o patologista apresenta os achados de seu estudo atestando a realidade dos fatos, revelando um diagnóstico definitivo, o ponto final (o momento final da vida) na cadeia de eventos ocorridos desde o início da doença.

Na perspectiva da patologia cirúrgica, diagnóstica, o diagnóstico é um ponto de partida, momento em que condutas médicas podem ser planejadas e postas em prática, na tentativa de modificar o curso de eventos, a história natural da doença. A partir desse ponto de vista, o diagnóstico está sempre se construindo, é dinâmico, na dependência do curso de eventos futu- ros, que podem desencadear novas interpretações dos achados. Essas interpretações é que vão subsidiar condutas médicas, mas a avaliação do desfecho, da resposta às condutas propostas, é que vai validar a interpretação que demos aos achados.

Ao avaliar a resposta do paciente às medidas terapêuticas instituídas, o diagnóstico proposto de abetalipoproteinemia demonstrou-se acertado, provocando uma modificação nas curvas de crescimento e ganho ponderal a partir do momento diagnóstico.

\section{FIGURA 2}

O momento do diagnóstico em relação às curvas de crescimento e ganho ponderal

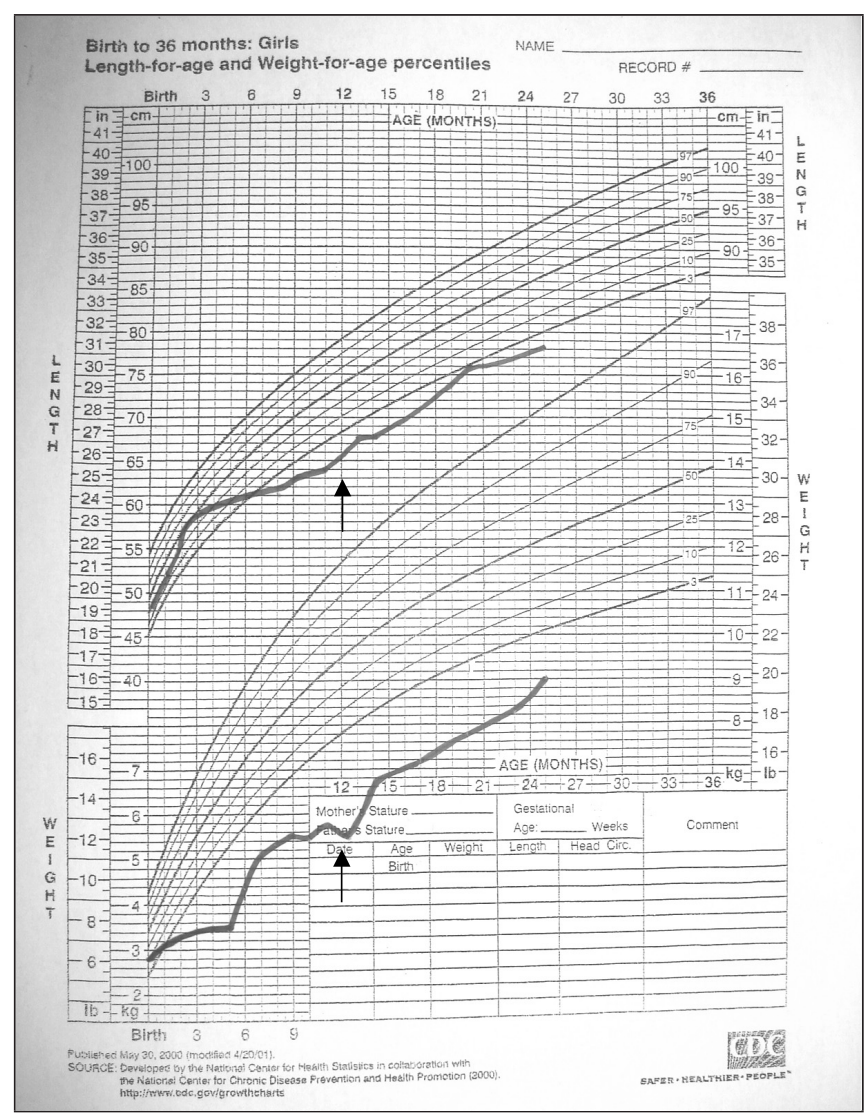

Curvas de crescimento e ganho ponderal: a partir do diagnóstico, na idade de 12 meses, há uma inflexão das curvas, que passam a se aproximar da curva do percentil 3. Até esse momento, a tendência era de se afastar dessa curva (Mattos et al. ${ }^{3}$ 2008).

\section{CONCLUSÕES}

As reflexões sobre a prática diagnóstica possibilitam um distanciamento da realidade, da concretude do caso e de seu conteúdo, de modo que os atores do caso, médicos envolvidos na assistência ao paciente, possam refletir sobre a própria prática. 
Nem sempre é possível extrapolar a outros casos o conteúdo apreendido, mas as reflexões sobre a prática possibilitam compreender a natureza de nosso trabalho, podendo ser aplicadas em outros casos.

As reflexões aqui feitas permitem compreender o diagnóstico não como uma verdade definitiva, mas como um momento de análise, um ponto de avaliação, a partir do qual podem ser instituídas condutas com o objetivo de modificar a história natural das afecções.

A possibilidade de que o diagnóstico represente a oportunidade de mudança do curso da doença implica um compromisso ético do patologista com o paciente. Esse compromisso se renova a cada amostra avaliada, exigindo a dedicação do patologista na avaliação do caso. Isto se aplica a qualquer caso, até mesmo a uma citologia cérvico-vaginal para rastreamento do câncer de colo uterino. A busca por uma célula alterada, displásica, pode significar a oportunidade de um tratamento precoce, ainda na fase pré-neoplásica. Deixada ao seu curso natural, a alteração displásica pode evoluir para uma neoplasia maligna, resultando eventualmente na morte do paciente.

\section{REFERÊNCIAS}

1. Peh WCG, Ng KH. Basic structures and types of scientific papers. Singapore Med J. 2008; 49(7):522-4.

2. Freire P. Pedagogia do oprimido. 44 ed. São Paulo: Paz e Terra; 2006.

3. Mattos FF, Péret Filho LA, Melo SFO, Malheiros RS, Moreira, AM, Pena GPM. Abetalipoproteinemia: case report [online]. 3th World Congress of Pediatric Gastroenterology, Hepatology and Nutrition; 16-20th augst. 2008. [acesso em 31 ago. 2009]. Disponível em: http://journals.lww. com/jpgn/Documents/World $\% 20$ Congress $\% 202008 \% 20$ abstracts.pdf

4. Bassen FA, Kornzweig AL. Malformation of the erythrocytes in a case of atypical retinitis pigmentosa. Blood. 1950;5:381-7.

5. Singer K, Fisher B, Perlstein MA. Acanthrocytosis: A Genetic Erythrocytic Malformation. Blood. 1952;577-91.

6. Druez G. Un nouveau cas d'acanthocytose: dysmorphie erythrocytaire congenitale avec retinite, troubles nerveux et stigmates degeneratifs. Rev Hemat. 1959;14:3-11.

7. Salt HB, Wolff OH, Lloyd JK, Fosbrooke AS, Cameron AH, Hubble DV. On having no beta-lipoprotein: a syndrome comprising abetalipoproteinaemia, acanthocytosis and steatorrhoea. Lancet. 1960;276:325-9.

8. Muller DPR, Lloyd , JK, Bird, AC. Long-term management of abetalipoproteinaemia. Possible role for vitamin E. Arch Dis Child. 1977;52:209-14.
9. Glickman RM, Green PH, Lees RS, Lux SE, Kilgore A. Immunofluorescence studies of apolipoprotein B in intestinal mucosa. Absence in abetalipoproteinemia. Gastroenterology. 1979; 76:288-92.

10. Dullaart RP, Speelberg B, Schuurman HJ, Milne RW, Havekes LM, Marcel YL, et al. Epitopes of apolipoprotein b-100 and b-48 in both liver and intestine. Expression and evidence for local synthesis in recessive abetalipoproteinemia. J Clin Invest. 1986;8:397-404.

11. Lackner KJ, Monge JC, Gregg RE, Hoeg JM, Triche TJ, Law $\mathrm{SW}$, et al. Analysis of the apolipoprotein b gene and messenger ribonucleic acid in abetalipoproteinemia. J Clin Invest. 1986; 78:1707-12.

12. Wetterau JR, Aggerbeck LP, Bouma ME, Eisenberg C, Munck A, Hermier M, et al. Absence of microsomal triglyceride transfer protein in individuals with abetalipoproteinemia. Science. 1992; 258:999-1001.

13. Shoulders CC, Brett DJ, Bayliss JD, Narcisi TM, Jarmuz A, Grantham TT, et al. Abetalipoproteinemia is caused by defects of the gene encoding the $97 \mathrm{kda}$ subunit of a microsomal triglyceride transfer protein. Hum Mol Genet. 1993;2:2109-16.

14. Rehberg EF, Samson-Bouma ME, Kienzle B, Blinderman L, Jamil H, Wetterau JR, et al. A novel abetalipoproteinemia genotype - identification of a missense mutation in the 97kda subunit of the microsomal triglyceride transfer protein that prevents complex formation with protein disulfide isomerase. J Biol Chem. 1996;271:29945-52.

15. Conticello SG. The AID/APOBEC family of nucleic acid mutators. Genome Biology. 2008;9:229.

16. Hajdu SI. Differential diagnosis of soft tissue and bone tumors. Philadelphia: Lea \& Febinger; 1986.

17. Rosai J. Guiding the surgeon hand. The history of the american surgical pathology. Washington: American Registry of Pathology and Armed Forces Institute of Pathology;1997. p.1-5: Some considerations on the origin, evolution, and outlook of American surgical pathology.

\section{CONFLITO DE INTERESSES}

Declarou não haver.

\section{ENDEREÇO PARA CORRESPONDÊNCIA}

Gil Patrus Mundim Pena

Rua Uberaba, 418 sl. 102

Barro Preto - Belo Horizonte

CEP. 30180-080 MG

E-mail: gilpena@gold.com.br 